\title{
BMJ Health \& Care Informatics \\ Turbulence health systems: engineering a rapidly adaptive health system for times of crisis
}

\author{
Enrico Coiera (1) , Jeffrey Braithwaite
}

To cite: Coiera E, Braithwaite J. Turbulence health systems: engineering a rapidly adaptive health system for times of crisis. BMJ Health Care Inform 2021;28:e100363. doi:10.1136/ bmjhci-2021-100363

Received 08 June 2021 Accepted 03 August 2021

Check for updates

(C) Author(s) (or their employer(s)) 2021. Re-use permitted under CC BY-NC. No commercial re-use. See rights and permissions. Published by BMJ.

Australian Institute of Health Innovation, Macquarie University, Sydney, New South Wales, Australia

Correspondence to Professor Enrico Coiera; enrico.coiera@mq.edu.au
The coronavirus epidemic has provided us a teachable moment in how to run a healthcare system. Dealing with this pandemic has required near-wartime levels of health system reconfiguration and reinvention-often with heroic effort and unprecedented commitment of resources. By the time this pandemic is over, we will have learnt much about how to manage the next one. ${ }^{12}$ Innovations in contact tracing, vaccine engineering, accelerated research translation through open science and in public health interventions will all make managing a future pandemic easier.

Our problem is that the next crisis will not be like the last one. Indeed, it is not hard to imagine a future where the health system suffers shock after shock from climate changetriggered mass events like floods and fires, to new pandemics, and social and geopolitical unrest. If it took a heroic response to get us through COVID-19, how could a health system survive many such challenges and in short order? Even resilient systems eventually fracture under repeated stress.

Somehow, we will need to engineer a health system that can bend and stretch its resources and capabilities, quickly and repeatedly. Like a chameleon, it will need to reconfigure to different contexts, never having a 'true' shape. It will be liminal, defined by the potential behaviours it could exhibit. We might call this a 'turbulence system'-one purpose-designed to operate across a wide variety of conditions and to efficiently and effectively reconfigure itself to meet different demands. ${ }^{3}$ Turbulence systems would recognise threatening system shocks as early as possible to provide time to reconfigure and will deploy a range of strategies to first prepare for, and then ride out, a system-wide shock.

How will a turbulence system in healthcare function? If it were an immune system, it would rely on antibodies to respond to those pathogens it has seen before. When faced with a novel threat, non-specific immune responses hold the fort until such antibodies are developed. It is the same for a turbulence system. A new pandemic will largely be dealt with using the infrastructure and know-how built for the previous one. Other shocks, however, may require new ideas and new tools.

This dynamic balancing between precommitted resources using pre-emptively designed strategies with just-in-time strategies to handle novel situations is a familiar one. In health informatics, the tools we use are drawn from a continuum of general-purpose technologies which focus on communication, through to highly designed digital systems crafted to support well-understood tasks. ${ }^{4}$ When at its best, our day-to-day work blends the use of tools like electronic records and decision support systems to deal with the expected, and a range of generalist tools like voice and text communication to deal with novelty, complexity and inefficiency.

So, what generalist tools and strategies might a turbulence-ready health system adopt? The first tranche are tools that aggregate and analyse data at every stage of a system shock, from early warning to finale. If we are to make decisions under uncertainty, then access to high-quality data that can convert the unknown to the known will be critical. ${ }^{5}$ Data sharing is essential-a feature of the early stages of the COVID-19 pandemic was a deep asymmetry of distribution and quality of pandemic data when some nations had few cases and others struggled to cope. The many technical, privacy, ethical and commercial barriers to capturing and sharing clinical data sets remain formidable, whether at the level of health service, region, nation or globally. If we are to shock-proof our national health systems, we must accelerate our data capture and sharing efforts.

Managing data synthesis and interpretation is also challenging. The COVID-19 Living Evidence Project had indexed about 160000 
peer-reviewed publications by the end of May $2021 .{ }^{6}$ Manual analysis of such a volume of science, of varying provenance and quality, with much duplication and reuse of the same patient data, has stretched our sense-making capacity. Automated tools will eventually do the bulk of this evidence synthesis using methods from artificial intelligence. Systematic reviews will be automated ${ }^{78}$; clinical trial and observational data will be analysed on the fly, ${ }^{9}$ answering both patient-specific questions as well as issues of policy, public health and system configuration, often in real time. We will synthesise quantitative and qualitative data, and this data fusion will have to accommodate a variety of data types including measurements, text, speech and images. ${ }^{10}$

While we cannot predict all the questions that will be asked of us, we must be prepared to quickly find the answers. This task cannot be solved by automation alone, especially when system shocks present novel challenges. Coalitions of humans and machines will come together physically or virtually at interagency 'fusion centres' to overcome compartmentalisation. ${ }^{11}$ This will permit us to synthesise different streams of emerging evidence, ask critical questions, simulate possible scenarios, formulate strategies, and deploy people and resources. Achieving this will require an integrated and sophisticated communication infrastructure. The command structure that governs this will have aspects of top-down and bottom-up control, but will most likely need a flexible middle-out approach. ${ }^{12}$

Highly specific strategies will complement these general ones. Rapid system reconfiguration and surge capacity will require a rapid response infrastructure to be in place. The emergence of mRNA technologies and the capacity to rapidly design and produce novel vaccines or other molecules may be among the greatest rapid-response gifts of the COVID-19 pandemic. ${ }^{13}$ Machine learning and other artificial intelligence methods will help optimise resource allocation across health services, predicting patient demand and identifying spare capacity. ${ }^{14}$ Traditionally backroom systems for supply-chain management become front-line weapons in a crisis. The COVID-19 pandemic is as much a story about early failures to manufacture, secure and deploy appropriate personal protective equipment and ventilators, as it is of panic buying of foodstuffs and consumer goods. We have much to learn from companies like Amazon on how to manage supply lines and shift supplies to where they are most needed as early as possible. ${ }^{15}$ We also need information systems to quickly identify functionally equivalent products or services that are substitutable or reconfigurable in a time of crisis, from finding spare hospital beds that can be used for intensive care patients to computer chips to build urgently needed devices. We also need to know how to make technologies interoperate 'just enough' to work together, even when they are built to different standards.

This may all seem too hard and not worth the price. Engineering a turbulence-ready health system will push our understanding of engineering complex adaptive systems and require new investment into an already resourcestretched sector. As memories of COVID-19 begin to fade, the desire to return to 'normal' will be strong. However, we do not have that luxury. Climate change looms over us all. New pandemics are certain. Global financial and geopolitical uncertainty is increasing. Old political allegiances are fracturing. If we wish to flourish or even just make do in this emerging reality, we will need to do more than create a learning health system that learns from the past. We must build a health system prepared to face that which cannot be foreseen.

Contributors EC conceived of and wrote the first draft, and JB provided critical feedback and revised the draft.

Funding This study was funded by National Health and Medical Research Council (Centre for Research Excellence in Digital Health).

Competing interests None declared.

Patient consent for publication Not required.

Provenance and peer review Commissioned; internally peer reviewed.

Open access This is an open access article distributed in accordance with the Creative Commons Attribution Non Commercial (CC BY-NC 4.0) license, which permits others to distribute, remix, adapt, build upon this work non-commercially, and license their derivative works on different terms, provided the original work is properly cited, appropriate credit is given, any changes made indicated, and the use is non-commercial. See: http://creativecommons.org/licenses/by-nc/4.0/.

ORCID iD

Enrico Coiera http://orcid.org/0000-0002-6444-6584

\section{REFERENCES}

1 Braithwaite J, Tran Y, Ellis LA, et al. The 40 health systems, COVID-19 (40HS, C-19) study. Int J Qual Health Care 2021;33:mzaa113.

2 Durski KN, Osterholm M, Majumdar SS, et al. Shifting the paradigm: using disease outbreaks to build resilient health systems. BMJ Glob Health 2020;5:e002499.

3 Coiera E, Magrabi F, Sintchenko V. The centre for health informatics at the University of new South Wales-a clinical informatics research centre. Yearbook of Medical Informatics 2007;16:141-8.

4 Coiera E. When conversation is better than computation. J Am Med Inform Assoc 2000;7:277-86.

5 Basit MA, Lehmann CU, Medford RJ. Managing pandemics with health informatics: successes and challenges. Yearb Med Inform 2021. doi:10.1055/s-0041-1726478. [Epub ahead of print: $21 \mathrm{Apr}$ 2021].

6 Project C-OA. Living evidence on COVID-19 2020. Available: https:// ispmbern.github.io/COVID-19/living-review/

7 Tsafnat G, Dunn A, Glasziou P, et al. The automation of systematic reviews. BMJ 2013;346:f139.

8 van Dinter R, Tekinerdogan B, Catal C. Automation of systematic literature reviews: a systematic literature review. Information and Software Technology 2021;136:106589.

9 Gallego B, Walter SR, Day RO, et al. Bringing cohort studies to the bedside: framework for a 'green button' to support clinical decisionmaking. J Comp Eff Res 2015;4:191-7.

10 Rapport F, Braithwaite J. Are we on the cusp of a fourth research paradigm? predicting the future for a new approach to methods-use in medical and health services research. BMC Med Res Methodol 2018;18:131.

11 Catano V, Gauger J. Information fusion: intelligence centers and intelligence analysis. Information sharing in military operations. Springer, 2017: 17-34.

12 Coiera E. Building a national health it system from the middle out. $J$ Am Med Inform Assoc 2009;16:271-3.

13 Meng C, Chen Z, Li G, et al. Nanoplatforms for mRNA therapeutics. Advanced Therapeutics 2021;4:2000099.

14 Strömblad CT, Baxter-King RG, Meisami A, et al. Effect of a predictive model on planned surgical duration accuracy, patient wait time, and use of presurgical resources: a randomized clinical trial. JAMA Surg 2021;156:315-21.

15 National Academies of Sciences, Engineering, and Medicine. Crisis standards of care: ten years of successes and challenges: proceedings of a workshop. Washington, DC: The National Academies Press, 2021. https://doi.org/10.17226/25767 